\title{
The Successful Management of Programs for Human Factors Certification of Advanced Aviation Technologies
}

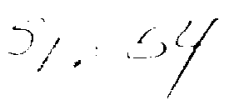

\author{
Rod Baldwin
}

Baldwin International Services

\section{Introduction}

In recent years there have been immense pressures to enact changes on the air traffic control organisations of most states. In addition, many of these states are or have been subject to great political, sociological and economic changes. Consequently, any new schemes must be considered within the context of national or even international changes.

Europe has its own special problems, and many of these are particularly pertinent when considering human factors certification programs. Although these problems must also be considered in the wider context of change, it is usually very difficult to identify which forces are pressing in support of human factors aspects and which forces are resisting change.

There are a large number of aspects which must be taken into account if human factors certification programs are to be successfully implemented. Certification programs would be new ventures, and like many new ventures it will be essential to ensure that managers have the skills, commitment and experience to manage the programs effectively. However, they must always be aware of the content, and the degree of certainty to which the human factors principles can be applied - as Debons and Horne (1993) have carefully described.

It will be essential to avoid the well known pitfalls which occur in the implementation of performance appraisal schemes. While most appraisal schemes are usually extremely well thought out, they often do not produce good results because they are not implemented properly and staff therefore do not have faith in them. If the manager does not have the commitment and interest in his/her staff as human beings, then the schemes will not be effective.

Thus, one aspect of considering human factors certification schemes is within the context of a managed organisation. This paper outlines some of the management factors which need to be considered for the air traffic control services. Many of the points received attention during the plenary sessions while others were covered by the working groups when the question arose of how various aspects of human factors certification programs would be managed.

Management and organisational issues will certainly need to be included in any frame of reference by those who may be involved in developing certification programmes.

Human Factors Certification of Advanced Aviation Technologies Edited by J. A. Wise, V. D. Hopkin, and D. J. Garland

Copyright 1994 Embry-Riddle Aeronautical University Press

PRECEDHG PAGE BLAIK NOT FHMIED

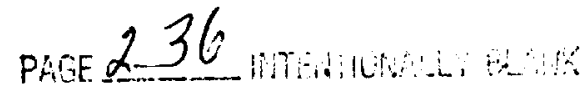




\section{Definition of Human Factors}

The concept of human factors issues is broad and still somewhat vague as the subject tends to include any aspect of human behaviour. However, experience in the design, operation and maintenance of large and advanced systems has shown that there is a human element which needs to be more carefully considered if the system is to perform as required. Unfortunately, there are still too many glaring examples of poor human factors aspects, and delegates to this workshop described numerous examples.

A formal definition of human factors is difficult, but many groups, such as The European Study Group for Human Factors in ATC (1991), have accepted the MANPRINT (1991) definitions of human factors as a useful guide:

- Manpower

- Personnel

- Training

- Human factors engineering

- System safety

- Health hazard assessment

\section{Attitudes}

There is no doubt that most management and certainly most employees in air traffic control have negative attitudes to the concepts of human factors and human-management techniques. Most instructors of management courses, especially those for technical personnel, know the problems which arise when it is suggested that there are theories for dealing with people. There is an initial suspicion that the instructor is suggesting that the theories will provide answers for dealing with Life, the Universe and Everything (Adams, 1982). It takes time to persuade them that the theories serve as a framework for putting the "human" problems into context and some theories can provide guidelines for dealing with the problems. When the term "psychological theory" is introduced, unease appears due to the trainees not appreciating the difference between psychologists and psychiatrists. The former implies that the other person is the problem, but that is OK, while the latter implies that I am the problem, and that is certainly not OK!

Such attitudes are varied between types of industry and the type of staff employed for certain types of work. Again, this varies from country to country and it is interesting to see the different responses to situations, such as those described above, by controllers and technicians from the various European countries in comparison to those from other countries.

It would be interesting to study the more highly educated leaders of the air traffic services, and see how receptive to human factors certification ideas they are, then compare them with those of more modest academic levels of achievement. Any such assessment would, of course, run into the problems of cultural issues. The latter aspects consistently arose during discussions, and there is no doubt that much more needs to be done in this area with respect to ATC if European integration is to be achieved successfully. 
The matter will certainly need to be addressed if such schemes are to have support from the tops of the organisations. With the decline of the renaissance man there are now too many managers who confuse the issue of human factors with the old themes of the Humanists and their suggestion that achievers are not sufficiently interested in the human being.

A regular comment at the workshop was the difficulty that human factors experts had in trying to communicate with top management. In practice, much of the misunderstanding and confusion is a result of fear that manifests itself in outright antagonism to acceptance of human factors issues. But of what are they afraid? Is it that the human factors experts are seen in the "parent" role? Perhaps they are identified with those other "parent" figures, the teacher/instructor/ lecturer/professor, who knew them so well and perhaps knew that they were not up to the job?

As usual, the writers of fiction are ahead of the managers of reality, as novelists can express their views without having to substantiate their comments or deal with the practical issues. Nevertheless, the comments can be valid and pertinent as is shown in the following quotation from Thomas Mann's "The Magic Mountain" (1960) where Settembrini says:

We humanists have all of us a pedagogical itch. Humanism and schoolmasters there is a historical connection between them, and it rests upon psychological fact: the office of schoolmaster should not - cannot - be taken from the humanist, for the tradition of the beauty and dignity of man rests in his hands. The priest, who in troubled and inhuman times arrogated to himself the office of guide to youth, has been dismissed; since when, my dear sirs, no special type of teacher has arisen. The humanistic grammar-school - you may call me reactionary, Engineer, but in abstracto, generally speaking you understand, I remain an adherent -

If we are to convince antagonists, we will need to answer such questions as: have managers rejected the values and urgings of the priest, will human factors experts have to overcome consequent feelings of guilt and is antagonism based on a feeling that if the human factors expert was good enough he/she would be in a line managerial job?

If the above ideas are correct, then the human factors experts will have to:

- Mount a massive public relations exercise to convince the line management staff that human factors issues are important,

- Give concrete evidence to line management staff that human factors schemes will increase performance, quality, capacity, etc.,

- Be prepared to give firm advice and say if human factors aspects are not satisfactory.

\section{Organisational Tasks}

Strictly speaking, the whole organisation should be analysed as a total system of interacting parts. However this does require great effort and it is questionable whether such a large "picture" is indeed meaningful.

However, this question may be answered by the present National Plan for Aviation Human Factors of the FAA (1990). The program is certainly comprehensive and realistically aims to put implementation responsibility down into each line unit of the organisation. 
It is often more appropriate to select a few key tasks of the organisation, starting with the end user of the system, and concentrate on the most significant interactions.

For instance, what do air traffic controllers actually do and how do they do it? When these aspects are established, we can provide better management for the activities in general and ensure that they receive all aspects of information support which they need - as opposed to what they think they need.

At present, there are a number of programs which are intended to address these matters. Unfortunately there was no mention at the workshop about the FAA's efforts with the SASHA programme, those undertaken for Eurocontrol by PA Management consultants as part of the EATCHIP programme and the studies, for the CAA of the United Kingdom being carried out at Roke Manor Research by Day (1993), and others.

However, the definition of the tasks must be related to the nature of the organisation, the type of management, and the leadership styles. The effect of the latter on the other aspects has been extensively studied (Handy, 1985) with particular attention given according to directive against consultative styles of management.

It is interesting that most staff seem to believe that a more consultative style of management will produce the best fits for achieving task requirements in conduction with the needs of the organisation, the team, and the individuals. That this is not necessarily so was indicated by Fiedler (1967), who has shown that both styles can be effective if used appropriately. He also states that an individual's style cannot be changed through training, as style is a stable characteristic of the individual. However, this view is refuted by Vroom (1973), who believed that a leadership development programme can enable a person to widen his or her range of management styles and so be more appropriate to a particular situation.

There is a need for a study of this contingency approach to leadership and management in the air traffic services in order to establish more understanding about the relationships between the different tasks. A very subjective attempt to place these factors onto a bar chart (Figure 1) shows up the wide misfit which can occur, and possibly explains why there are so many problems in the air traffic control services. These occur despite the evidence that controllers actually enjoy the detailed workings of their job, and that their monetary rewards are generally towards the higher end of the remuneration scale.

\section{Organisational Structure}

The type of organisation will play a significant role in how a certification programme is carried out. Unfortunately, many organisations have not fully clarified their objectives, how they are to be achieved, and how the various elements of the organisation relate to each other. Thus, misunderstandings and dissatisfaction will occur when an organisation attempts to introduce new schemes without having a clear understanding of the context into which the new scheme must fit. 


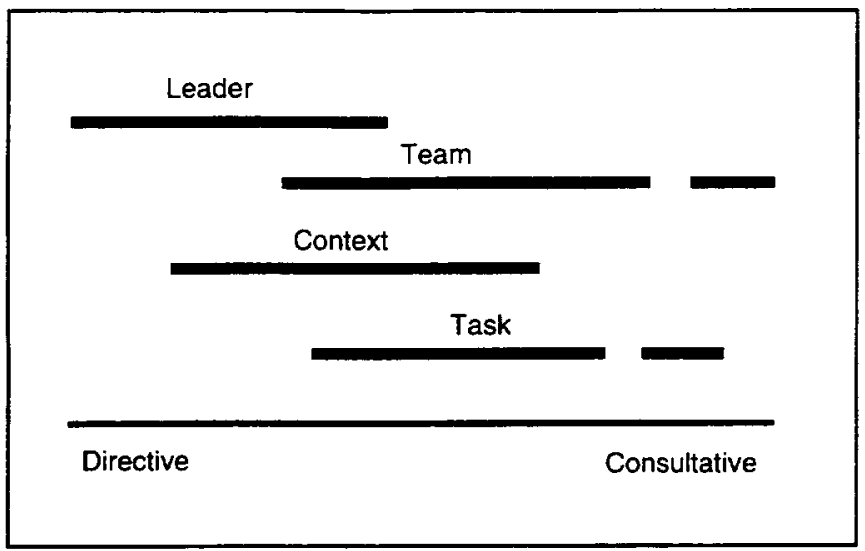

Figure 1. Management styles in ATC

Organisations can be classified in many different ways depending on performance or other criteria which need to be analysed. Burns (1968) distinguished three forms of organisation as mechanistic (i.e., bureaucratic), organistic (i.e., flexible), and pathological. Westrum (1993), however uses the more colloquial terms of normal, healthy, and sick!

Modern practice is to consider that individuals and teams can operate more effectively and with more motivation in organic style organisations as opposed to the more mechanistic forms. Thus, organisational development should start with a careful definition of the task or tasks to be achieved, and then consideration should be given to the individual and team requirements for maximum efficiency in achieving the task.

Most air traffic control organisations, however, have traditionally had a mechanistic structure, even, to some extent, with a slightly militaristic attitude. Now, many of them are (or have done so) attempting to change (with varying degrees of success) into organic forms in order to meet modern task and personnel requirements.

One of the dangers in attempting to change an organisation is the problem of becoming stuck in the pathological form. This can often come about by upper management trying to move the organisation from the mechanistic to the organic, but without wishing to lose the benefits of the former. Of course, "benefits" can imply material benefits or intellectual ones which provide a comfort zone based on previous experience.

This situation is particularly evident where government controls the organisation. This was recently seen in the case of Aer Lingus (1993) being required to become a realistic commercial operation but at the same time being directed by the government to operate its transatlantic flights via Shannon, which increased costs.

The present interest in privatisation - or more correctly "commercialisation" - of the air traffic control organisations has provided additional pressure for a move to more organistic organisational forms. But this in turn has necessitated a change in attitude among many staff who were formally civil servants. Unfortunately, in some cases a new problem has occurred through staff sectorisation because some of the changes have been more beneficial to certain personnel than others. Consequently, many of these organisations may be actually moving into the pathological state while offering a window dressing of go-getting private attitudes! 


\section{The Team}

In any organisation, there are many teams operating at different levels. These are mostly interdependent but effort has to be expanded by the management to ensure that each understands its role and its relationship to the other teams.

Definition of the organisation's task should start with the end user team, but this should not necessarily imply any superior position. In fact, each team should see itself as an end user of another teams product and a supplier of a product (perhaps as in-house consultants) to another team or teams.

However, superior teams will arise if certification programs are introduced for some personnel but not for others. Initially there may be acceptance of the situation, but whereas equipment has an accepted life span and generally keeps to that if the original specifications have been adhered to, humans have a habit of changing according to circumstances. Thus, certified but poorly performing individuals introduce accentuated problems into the teams.

Hence, certification programs must give close attention to team composition and the shelflife of the certified personnel! This therefore introduces the need for currency checking and the consequent costs of maintaining such programs. In addition, consideration must be given to the degree to which the certification process can slow down an operation and whether the process is counterproductive to ensuring that an organisation is adaptable to changing requirements as Hancock (1993) strongly urged.

The role of human factors auditing programmes needs much more consideration as a way to overcoming many of the disadvantages of certification as this process would also leave line managers in control of their operation.

\section{Regulation}

In Europe, there are a wide variety of certification standards and training schemes, and so mobility of staff is either difficult or impossible in many cases. There are two possible solutions if common acceptance is to be achieved:

- Each state could recognise the qualifications of personnel from other states; how the training was performed is the concern of each state. This, of course, requires a careful definition of what each qualification allows the holder to do and the context in which the task can be performed.

- The qualifications and training programmes are integrated throughout the European states. This requires very careful definition of the knowledge and skills which are required for the qualification, establishing other conditions which must be applied, and how standards are specified, set, and checked throughout the large number of states concerned.

At the moment, there appears to be pressure in Europe for the latter solution and a feeling that the problems can be overcome. The problem of maintaining common standards for training air traffic controllers was addressed by Baldwin (1988) some years ago, when he suggested the 
establishment of external examiners, where "external" means from another state. Initially, the external examiner would only act as an observer, but offer comments on how a similar situation would be addressed and dealt with in his/her own organisation. Naturally, there would be problems because each ATC system has grown up in its own way and comparisons are not very easy. However, as Europe moves towards an integrated system, then a common certification program becomes feasible.

A major requirement for these external examiners will be that they have a strong sense of tact and a serious desire to study the other country's system, appreciate how it is structured, how it operates, and the context of the operating system.

A similar scheme for the certification of aircraft is presently run by the Joint Aviation Authority (JAA), which is an associated body of the European Civil Aviation Conference (ECAC) through its MAST program. This consists of several expert groups being formed from staff of the member states but with a briefing from the Technical director of the JAA. These groups, in fact, are integration groups for the maintenance of standards and are therefore very welcome by each member state.

The JAA scheme is appropriate as aircraft are common to the various airlines of the different countries, and thus common requirements are relatively easy to apply. The same conditions will not apply to the air traffic control until there is an integrated system. However, a start will need to be made and there is no reason why some form of central bureau should not be established.

In fact, during the workshop an interesting exercise compared possible requirements for the certification of advanced air traffic systems with those presently applied to the certification processes of developing a new aircraft. This showed that much more thought needs to be given to which stages require the involvement of human factors specialists, to what extent they should be involved and who the specialists should be. In short, there appeared to be a need for a progressive change from human factors certification to checking, and then auditing as an overview.

Of course a major problem is that present organisations such as Eurocontrol, ECAC, the European Commission and the JAA need to redefine their terms of reference with respect to what they can best achieve, what they are good at, what authority they can wield and how they relate to each other.

\section{The Leader and Technological Change}

At one time, the leader could develop his or her technical skills, expand into leadership skills and then apply them until retirement. However, with the present rate of change, this method of working is no longer possible and, in fact, can cause obstruction to new schemes from the top.

Although this phenomena is not particularly new, it is so in terms of the rate of change together with the need to place more emphasis on the human factors elements. However, the workshop did bring out the fact that whilst many managers are expert in dealing with the component parts of systems, they might not be expert in dealing with the special aspects of the whole system - especially when it is advanced and large. As certification of the system therefore becomes particularly difficult, we will need to reconsider who should be carrying out the certification process, the methodology used and who endorses the certificates.

Toffler (1970) made an impact with his book Future Shock at the beginning of the seventies. In one section, entitled "Taming Technology" he noted: 
Given that a majority of men still figuratively live in the twelfth century, who are we even to contemplate throwing away the key to economic advance? Those who prate anti-technological nonsense in the name of some vague 'human values' need to be asked 'which humans'? To deliberately turn back the clock would be to condemn billions to enforced and permanent misery at precisely the moment in history when their liberation is becoming possible. We clearly need not less but more technology.

While many of these terms would need to be changed depending on the topic of discussion and the environment under consideration, there is no doubt that the views still echo much of the thinking in the air traffic services. Certainly, at the general discussion of the 1992 Advanced Study Institute (Wise, Hokin, \& Stager, 1993) there were many views expressing resistance to the introduction of advanced automation. At times, there appeared to be a mind-set on the role of humans and whether they should adapt to automation. The main problem was the mind-set. Are we locked into set opinions, politically correct thoughts? Will these proceedings be able to break out of this straightjacket?

For this workshop the constraint for consideration was the degree to which human factors experts would commit themselves to certification because of the question concerning validity, or just not wanting to commit themselves in the way that operational staff have to. To some extent the matter was addressed, but there is still a suspicion that discussion and advising is easier that giving firm recommendations!

Westrum (1991) has taken the theme further (chapter 8 of section 3, Originators and Managers of Technology) by analysing the intellectual resistance to innovation in terms of failures of imagination and failures of nerve. The examples given from military operations make useful parallels for air traffic where safety is the priority factor.

However, at a recent ATCA Conference (General Discussion, 1993), the message from many speakers was that we now have enough technology to meet whatever technical task is required. What is needed now is the individual and team ability to use the technology. Baldwin (1991) pointed out that if the human element is ignored in the present massive European expenditure on new air traffic control systems and equipment, then the result might be no air traffic control capacity increase at all!

\section{Conclusion}

The corner has been turned, but the human factors experts must conduct their work and present their results in forms which are readily understandable to the leaders, managers, engineers and operators. That is, the Human Factors experts must now study themselves and how they relate to their clients!

This message has been made several times in this paper and it was made strongly on the last morning of the workshop. 


\section{References}

Adams, D. (1982). Life, the universe and everything. New York: Simon and Schuster, Inc. Article (June 28-July 11, 1993), Aer Lingus Moves to Sell Hotels, Other Businesses, Commercial Aviation News, U.S.A.

Article (June 28-July 11, 1993), Europe Without Borders, Commercial Aviation News, U.S.A. Baldwin, R (1988), ATC 2000, Eurocontrol Institute, Luxembourg.

Baldwin, R (1991), Humans are the limit!, Flight International, 28 August-3 September. Burns, T., \& Stalker, G. H. (1968). The Management of Innovation. London: Tavistock.

Day, P. O., Hook, M. K., Warren, C. \& Kelly, C. J. (1993). The modeling of air traffic controller workload. Workload Assessment and Aviation Safety. Royal Aeronautical Society Conference (27/28 April), London, U.K.

Debons, A., \& Horne, E. H. (1994). Information system certification: Purview, perspective and projections. In J. A. Wise, V. D. Hopkin, \& D. J. Garland (Eds.), Human Factors Certification of Advanced Aviation Technologies. Daytona Beach, FL: Embry-Riddle Aeronautical University Press.

Federal Aviation Administration. (Draft, 1990, December). The National Plan for Aviation Human Factors. Washington, DC: U. S. Department of Transportation.

Fiedler, F. E. (1967). A Theory of Leadership Effectiveness. McGraw - Hill.

General discussion. (1992). Verification and validation of complex and integrated humanmachine systems. Vimeiro, Portugal: NATO Advanced Study Institute.

Hancock, P. A. (1994). Certifying life. In J. A. Wise, V. D. Hopkin, \& D. J. Garland (Eds.), Human Factors Certification of Advanced Aviation Technologies. Daytona Beach, FL: Embry-Riddle Aeronautical University Press.

Handy, C. (1985). Understanding Organisations. London, U.K.: Penguin Books.

Helms, J. L. (1993). Air Traffic Control Association (ATCA) Conference. Geneva, Switzerland.

Mann, T. (1924). The Magic Mountain (Translation). Penguin Books. (Original work published 1960).

The European Study Group for Human Factors in Air Traffic Control (1991). Terms of Reference.

Toffler, A. (1970). Future Shock. London: Pan Books.

U.K. Ministry of Defense Army Department DTI. (1991). MANPRINT. London: HMSO.

Vroom, V. H. \& Yetton, P. (1973). Leadership and decision-making. University of Pittsburgh.

Westrum, R. (1991). Technologies and society. Belmont, CA: Wadsworth Publishing Company.

Westrum, R. (1993). Cultures with requisite imagination. In J. A. Wise, V. D. Hopkin, \& P. Stager (Eds.), Verification and Validation of Complex Systems: Human Factors Issues. Berlin: Springer-Verlag.

Wise, J.A., Hopkin, V.D., Stager, P. (1993). Verification and Validation of Complex Systems. Berlin: Springer-Verlag. 
